\title{
AIRCRAFT ACQUISITION AND OPERATION IN A TOTAL QUALITY ENVIRONMENT \\ Part I: A Conceptual Framework and Approach
}

\author{
By \\ Mohamed M. Elmaadawy ${ }^{*}$ and Atef O. Sherif ${ }^{* *}$
}

\begin{abstract}
A conceptual framework and an approach for handling the problem of aircraft acquisition and operation in a total quality environment are proposed in this part of the work. For this purpose, a typical acquisition process is described and the system operational and maintenance support requirements are summarized. The Aircraft Mission Support Process (AMSP) is analyzed at different levels of detail to identify the problem symptoms, causes, statement, problem solving approach and the design alternatives. This provides the necessary background and foundation for establishing a Logistic Engineering Model to support the decision making during aircraft acquisition and operation. Statistical Process Control (SPC) and process capability measures are utilized in the decision making process. To support this concept, the intended model is further developed to provide sampling experiments to pursue the required statistical analysis. This is done by using aircraft operational availability as the external performance indicator for the Aircraft Mission Support Process. Internal performance indicators are also considered. This approach can provide a mechanism for evaluation of different acquisition and/or operation options directed to continuous improvement of aircraft readiness and utilization. Part II of this work presents (AMSP) modeling and improvement procedure.
\end{abstract}

\section{INTRODUCTION}

Acquisition and operation of aircraft systems in the new rapidly changing world environment has become complex and costly process. This is mainly attributed to the uncertainties associated with the acquisition process itself. The uncertainties arise from the rapid change in thought processes and actions related to the technologies and acquisition policies adopted by both aircraft users and suppliers. The existing methods and tools may not be adequate to support prediction of future process performance during the early phases of acquisition. As a result, user requirements may not be satisfied and high risk is involved. Total quality concepts and tools may provide reliable means to identify and solve such problems.

In the Total Quality Environment (TQE), problem solving is mainly based on the practice of continuously improve the performance of processes under consideration. This is performed under the umbrella of statistical methodologies that support the effort of monitoring and reducing the variability in the process output. For this purpose internal and external performance indicators (quality characteristics) are utilized to detect what is going within the process as it affects the overall process performance. This approach is typically utilized during the production phase of the aircraft. In this work the utilization of this approach is extended to

\footnotetext{
* Major General, EAF.

** Professor, Aeronautics Dept., Cairo University.
} 
support prediction and decision making in the early phases of aircraft acquisition. This is to insure that the aircraft is conceived, designed, and produced such that user operational and maintenance requirements are satisfied during the actual operation. Fig.1 shows the basic logic of problem solving in the total quality environment.

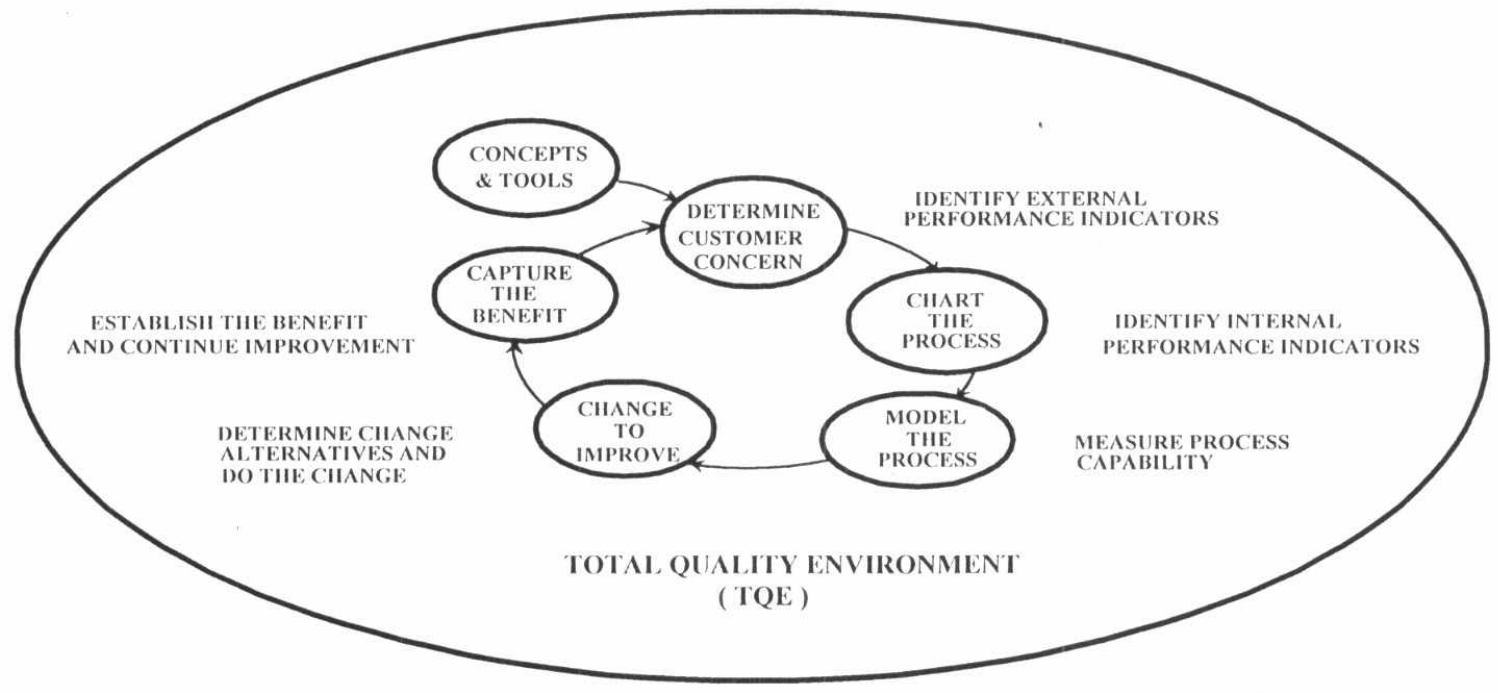

Fig.1. Problem Solving Approach in TQE [Ref. 5]

Prediction of future performance during aircraft acquisition is of vital importance to both the users and the suppliers. The application of Statistical Process Control (SPC) and process capability measures may provide the necessary means to correctly predict the future performance of an acquired aircraft system. This prediction would enable aircraft users and suppliers adopt the acquisition policy that reduces the risk involved and make design, support, and operational tradeoffs. The same principles may be applied whenever a changes in design or support are encountered during the operation phase of the aircraft.

Surveying of a group of references in the problem area indicates the following:

1- The aircraft operational availability is widely used as an external performance indicator ( $70 \%$ of the surveyed references) to support decision making during aircraft acquisition process as well as during actual aircraft operation.

2- Decisions taken during acquisition had great impact on the aircraft readiness during the actual operation [2].

3- The existing decision support models do not enable the application of statistical methodologies of controlling and predicting possible range of variation of the process future characteristics [15].

4- Establishing of correlation provides knowledge about the effect of the change in a set of causes on the measured characteristics. But, it does not provide means for prediction of the process future performance under the state of statistical control [4].

5- New modeling approaches are required to support the task of predicting process future performance. Dependence on full distribution of the measured characteristics instead of the mean value is strongly required [8]. 
6- It is necessary to provide an interfacing mechanism (or mutual understanding) between the aircraft users and suppliers during both acquisition and operation $[1,12,16]$.

7- Total Quality concepts and tools provide a new initiative directed towards improving total system quality. Application of these concepts and tools should further be explored in order to exploit/utilize their benefits [2].

8- To achieve performance improvement, actions should be started on the constraint resources first. Action on a process without performance improvement is waste[10].

9- The cost of R\&D efforts directed to improve aircraft design characteristics during acquisition should be balanced by a waste reduction resulted from better aircraft availability during operation [11].

The objective of this paper is to demonstrate a conceptual framework and approach for handling the acquisition and operation of an aircraft system in a Total Quality Environment. The concept is based on the utilization of statistical process control and process capability measure techniques in prediction and decision making.

\section{ACQUISITION OF AIRCRAFT SYSTEMS}

An aircraft system constitutes a complex combination of resources in form of people, material, equipment, software, hardware, facilities, etc.., integrated in such a manner as to fulfill a designated operational need. System acquisition refers here to the process of acquiring a system for operational use based on initially defined need. The objective is to develop and produce a configuration that will accomplish all functions as defined and incorporate the essential characteristics of performance, effectiveness, and quality [3].

Fig.2 shows a typical aircraft system life cycle. The first four phases represent the acquisition process of that system while the first three phases represent the elements of the system engineering process.

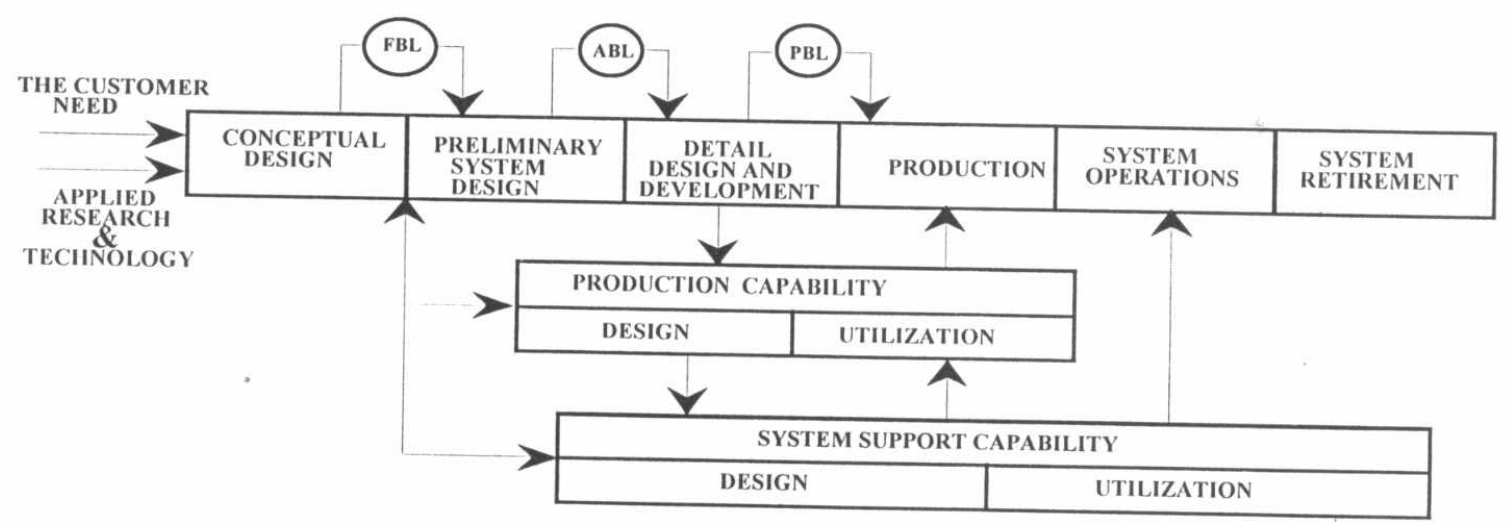

Fig.2. Aircraft System Acquisition/Life Cycle [Ref. 3]

The system engineering process commences with the identification of the need and the establishment of requirements, constraints and design criteria. On the basis of the results, Functional Base Line (FBL), Allocated Base line (ABL), and Production Based Line (PBL)
configurations are generated. 
Fig. 3 shows the process and directions of design influence and resource identification during aircraft system engineering. This is performed by application of "Logistic Engineering Models" to conduct high level system analysis and performance prediction. Such models, are usually classified as Computer-Aided Acquisition and Logistic Support (CALS) models [3].

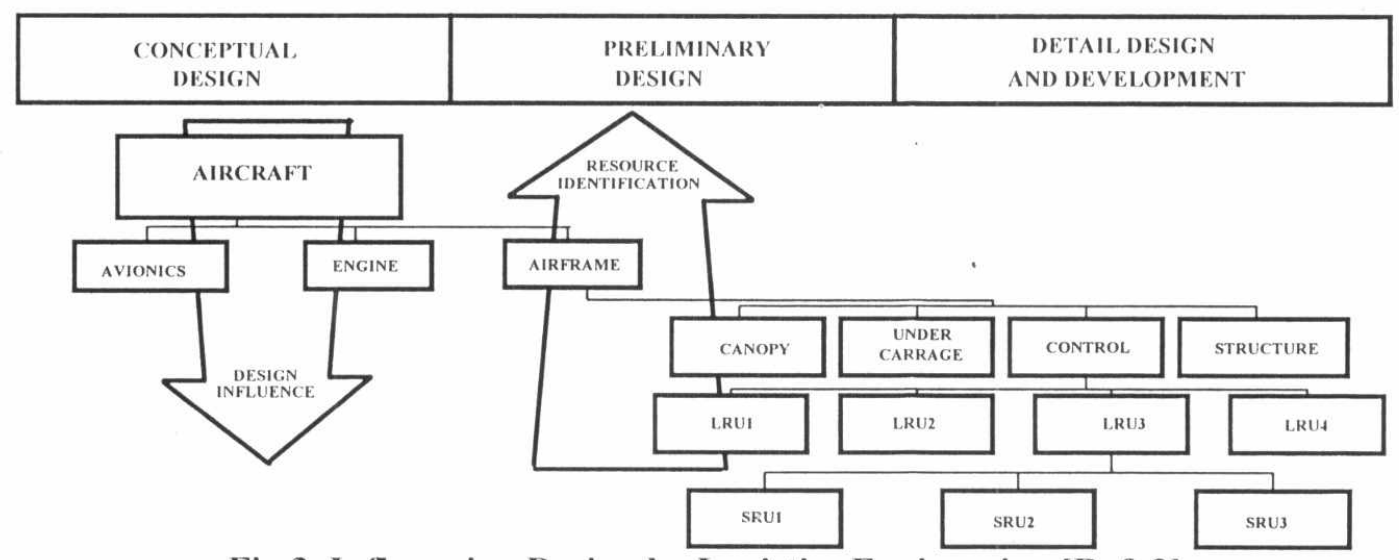

Fig.3. Influencing Design by Logistics Engineering [Ref. 3]

The design characteristics of aircraft and the related support configuration are determined during the aircraft system engineering process. This will establish the set of causes that affect future aircraft readiness and utilization. Tradeoff studies and performance prediction are then performed to evaluate the various alternative sets of causes that are feasible in meeting the user operational and maintenance support requirements. The output of these studies should reflect a preferred system configuration and a low acquisition risk. This can be decided by predicting the capability of supporting aircraft missions when deployed for operation.

\section{Operational and Maintenance Support Requirements}

The anticipated operational use of the aircraft system is ,say, 20 years during which the system is expected to meet certain operational and maintenance requirements. The support of these requirements is usually based on operation and maintenance considerations summarized in the flow diagram shown in fig.4.

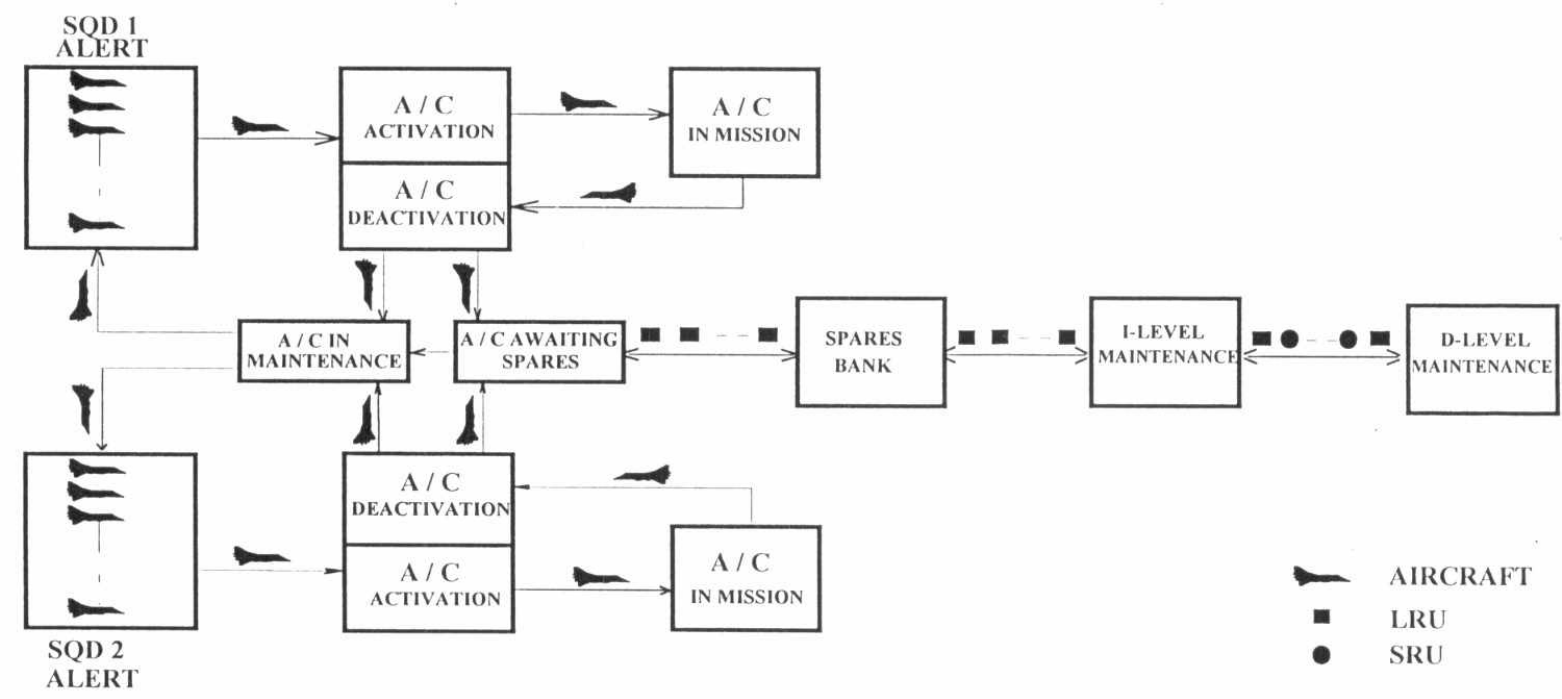

Fig.4. A/C System Operation and Maintenance Flow Diagram 
The aircraft are distributed on two operational squadrons. Each squadron occupy a different alert area, but they have common maintenance area and competing for the assets in the same spare bank. A typical situation defines a primary mission, may be Air To Air, while the secondary mission may be Air To Ground. Missions are executed in pairs of aircraft $(2,4,6$, or 8 aircraft) and mission duration is characterized by a normal distribution, say, of mean 60 min., with no aerial refueling. Time of activation and deactivation of missions are usually characterized by log normal distribution, say, of mean 60 and $40 \mathrm{~min}$. respectively. These operational requirements are to be accomplished within a specified budget and a demonstrated capability to provide minimum operational availability $\left(A_{O}\right)$, say, of $70 \%\left(70 \% \leq A_{O} \leq\right.$ $100 \%$ ) and utilization rate of $15 \mathrm{hr} / \mathrm{ac} / \mathrm{mo}$. Maintenance requirements are typically based on the concept of three levels of maintenance. Table 1 shows the characteristics of this concept.

Table 1 Aircraft Maintenance Concept

\begin{tabular}{|c|c|c|c|}
\hline Maintenance Level & Responsibility & Type of Maintenance & $\begin{array}{c}\text { Average Repair } \\
\text { Time }\end{array}$ \\
\hline Organizational & User & On Aircraft & $120 \mathrm{~min}$. \\
\hline Intermediate & User & Component Repair & 15 days \\
\hline Depot & Supplier & $\begin{array}{c}\text { Component and } \\
\text { Sub-Component repair }\end{array}$ & 180 days \\
\hline
\end{tabular}

\section{Aircraft Mission Support Process (AMSP)}

Aircraft Mission Support Process includes all the logical and physical elements of supporting the operation and maintenance of an aircraft to fulfill its assigned mission [9]. In (TQE), the concept of extended process is considered. This term refers to the expansion of the organization to include suppliers of inputs and the customers or user of outputs. Fig. 5 is a pictorial view of the extended process of aircraft mission support.

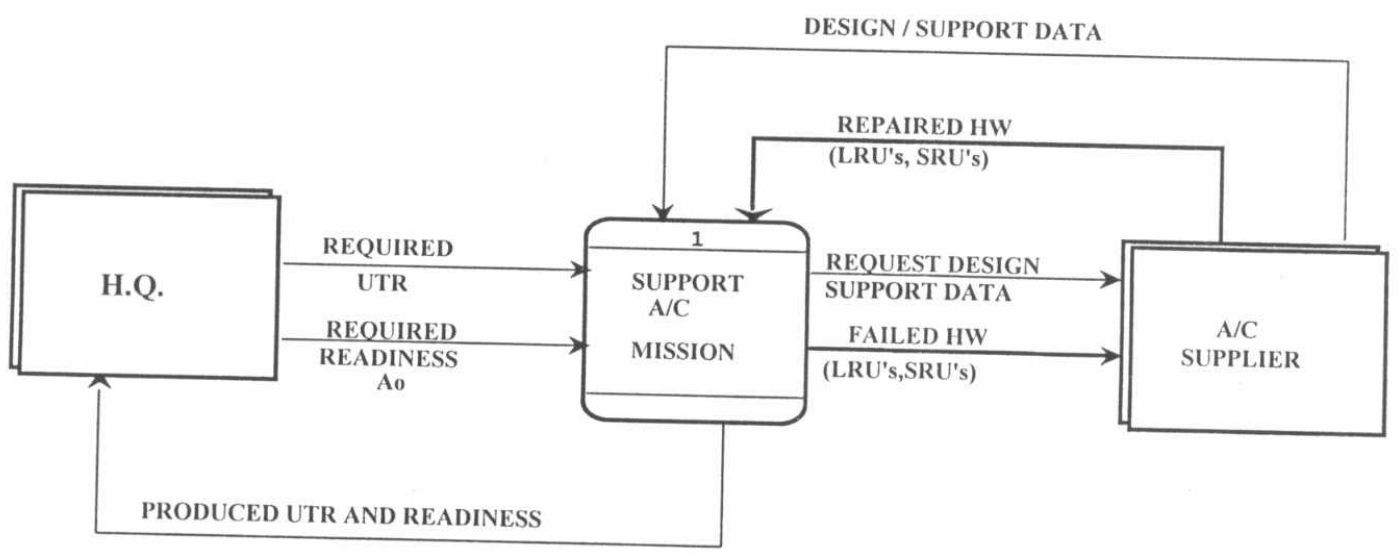

Fig.5. Aircraft Mission Support Process (Symbology of Ref. 6)

The extended process begins by communicating the needs of the customer, i.e. the Head Quarters (HQ). At the other end of the process is the supplier (aircraft production company/depot level maintenance facility). The organization, which is the operator of the aircraft system (i.e. the owner of the process), communicates the needs and expectations of its 
customers to its supplier so that the supplier can help improve customer satisfaction. This can be realized by showing that (AMSP) is capable of providing these needs and meeting these expectations.

Measuring of (AMSP) performance should be conducted externally on the process level and internally on the sub-process level. To accomplish the required measurements, Aircraft Operation Availability $\left(A_{O}\right)$ is taken as the process external performance indicator. Mission Waiting Time (MWAIT), Scheduled Maintenance Queue length (SMQ), and aircraft NonMission Capable (NMC) are established as internal performance indicators for sub processes $1.3,1.4$ and 1.5 respectively as shown in fig. 6 .

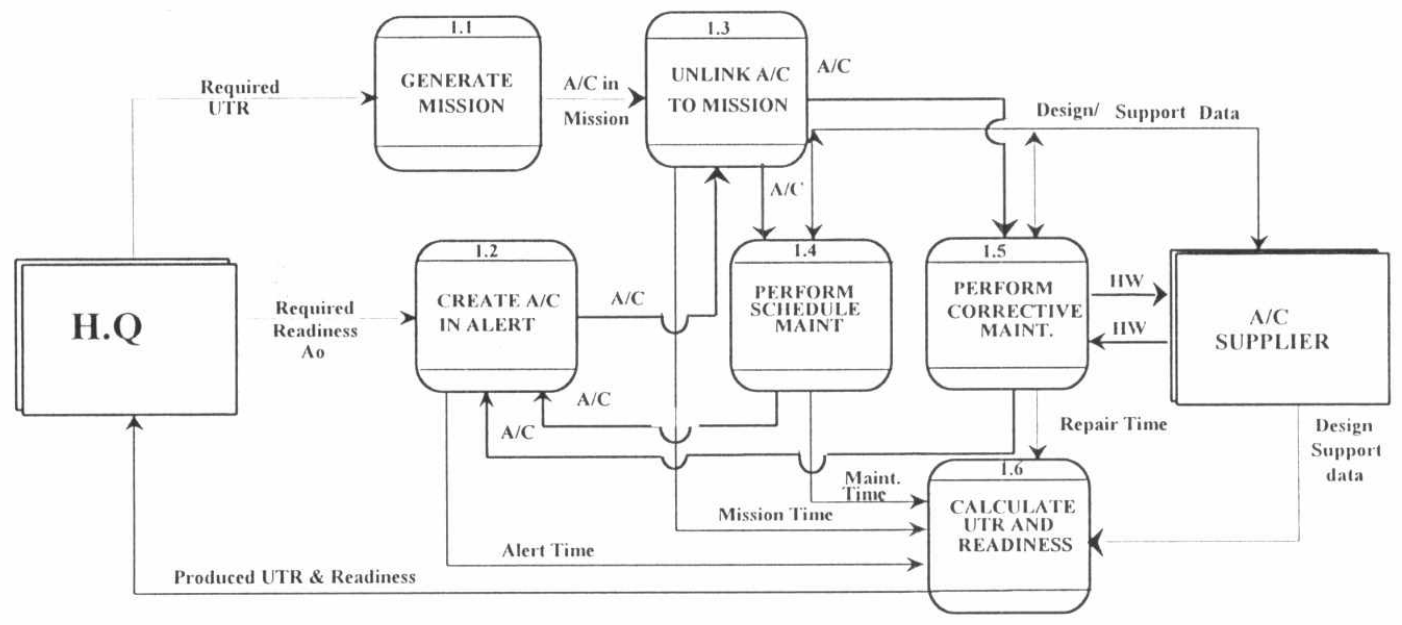

Fig.6. Aircraft Mission Support Process (2nd. Level of Detail)

\section{Aircraft Operational Availability $\left(\mathrm{A}_{0}\right)$}

Systems such as aircraft and their constituent functional systems (e.g. navigation, communication, weapon delivery, etc.) are used intermittently either on a scheduled or emergency basis for a fraction of their uptime. In this case $\left(A_{O}\right)$ is defined as the percentage of total calendar time that they are in an up state.

$$
A_{\circ}=\frac{U_{p} t i m e}{\text { Uptime }+ \text { Downtime }}
$$

Where: Uptime is the sum of the ready (alert) time and the operation time.

Equation (1) for $\left(\mathrm{A}_{\mathrm{O}}\right)$ indicates that for a fixed total time (Uptime + Downtime), continuous improvement of aircraft readiness can be achieved through the continuous reduction of aircraft downtime. Actually, $\left(\mathrm{A}_{\mathrm{O}}\right)$ is initially controlled by the supplier through the design characteristics of the aircraft. Then, it is partially controlled by the user during the operation phase by manipulating the operation, support and administrative factors.

Fig.7 shows a Cause and Effect (C\&E) diagram that characterize the aircraft operational availability. This is an output of a Process Action Team (PAT) effort in which the five most likely causes of Downtime (or uptime constraints) affecting $\left(\mathrm{A}_{\mathrm{O}}\right)$ are circled. 


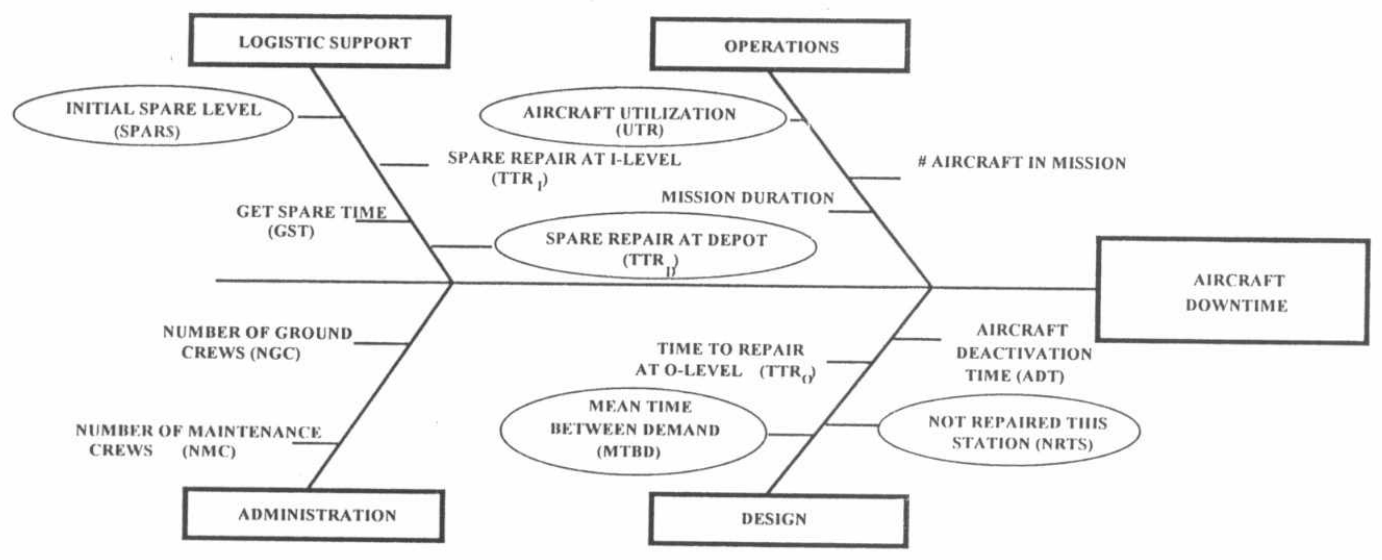

Fig.7. Operational Availability C\&E diagram.

Table 2 shows the controllability of the most likely factors that affect $\left(\mathrm{A}_{\mathrm{O}}\right)$ at different phases. These factors, as an integrated set of causes, shape the readiness and utilization characteristics of the aircraft system during the operation phase.

Table 2 Controllability of Factors

\begin{tabular}{|c|c|c|}
\hline Phase & Controls (causes) & Controlled By \\
\hline Design/Development & MTBD, NRTS & Supplier \\
\hline Production & SPAR\$ & Supplier/User \\
\hline Operation & UTR, TTR $_{\mathrm{D}}$, SPAR $\$$ & User/Supplier \\
\hline
\end{tabular}

\section{Change Alternatives}

Improvement of aircraft system readiness may be obtained through reduction of system downtime. Considering $\left(\mathrm{A}_{\mathrm{O}}\right) \mathrm{C} \& \mathrm{E}$ diagram fig.8, potential alternatives to improve aircraft readiness and utilization, for a given fleet size and budget are :

1- Improve reliability/maintainability to increase $\mathrm{MTBD}_{\mathrm{min}}$.

2- Modify/Redesign test and support equipment to decrease NRTS $_{\max }$.

3- Increase the initial spares stock level (i.e. increase SPAR\$).

4- Decrease Spare Repair Time at the depot level of maintenance (i.e. decrease TTRD)

5- Adopt different utilization (UTR) levels based on the available budget.

Any subset of the above set of potential system changes (or designs), within the constraints of budget, will be considered as a feasible alternative.

\section{PROBLEM IDENTIFICATION}

Problem identification includes the determination of symptoms, causes, statement of the problem, and the problem solving approach.

\section{Problem Symptoms}

A new acquired aircraft system, when deployed for operations, behaves differently from what was expected by the system user. Aircraft operational availability may be low and highly 
variable. Also, system operating cost may be high and the required utilization is difficult to attain. This may degrade the system readiness and threatens the national security of the purchasing country.

\section{Problem Causes}

The unexpected performance and the inconsistent behavior of an acquired aircraft system, when happen, may be attributed to the failure of user or supplier prediction capacity. One reason for this failure is the use of inconvenient analytical tools in prediction. For example, Process characteristics can not be quantified as, say $\mathrm{A}_{\mathrm{O}}=0.75$. This means that classical probability provides no measure of capability or means for prediction. Process characteristics have a past, present and could have a future. Prediction of the future requires that probabilities concerning process characteristics are obtained empirically through experimentation [7]. Also, using of mean values and confidence intervals has no operational meaning. It may be useful to summarize the results of an enumerative study but not for describing the dynamic behavior of a process in future. Besides, measurements are misleading when performed on unstable processes. The process should be random and statistically controllable to have a definable identity and be predictable into the future [15].

\section{Problem Statement}

Using Total Quality concepts and tools, it is required to develop a performance prediction tool by providing a capability measure for the Aircraft Mission Support Process to support decision making during aircraft acquisition and operation.

\section{Problem Solving Approach}

The following steps are suggested to establish the required problem solving approach:-

1- Model the Aircraft Mission Support Process (AMSP) with the inclusion of design, operation, support, and administrative factors shown in the C\&E diagram, fig.7.

2- Utilize the aircraft operational availability $\left(A_{O}\right)$ as an external performance indicator for the Aircraft Mission Support Process (AMSP).

3- Adopt simulation in modeling of (AMSP) to perform simulation experiments and overcome the constrains imposed by analytical modeling approach.

4- Construct quality control charts then utilize Statistical Process Control (SPC) and process capability measures to control and predict (AMSP) future performance.

5- Implement the model using suitable simulation tools on a Personal Computers.

\section{APPLICATION}

To demonstrate the power of the proposed concept and approach, a sample case is considered. It represents an acquisition of a fleet of fighter aircraft. The following is a proposed decision making (improvement) procedure:- 
1- Define the initial characteristics of the acquired system such that all design, support, operational data input to the model are provided.

2- Use the developed Logistic Engineering Model to perform a set of sampling experiments to cover, say, 10 years of aircraft operation.

3- Construct $\mathrm{X}-\mathrm{BAR}$ and $\mathrm{S}$ charts for $\left(\mathrm{A}_{\mathrm{O}}\right)$. Stabilize and control the process by omitting the samples of the transient period. Then calculate the process capability index Cpk.

4- If the process is incapable (i.e. Cpk $<1$ ), make the necessary changes (design, support, operational) and repeat the improvement cycle until Cpk $\geq 1$.

Fig. 8 and fig.9 show a process capability study for three different acquisition policies (options).

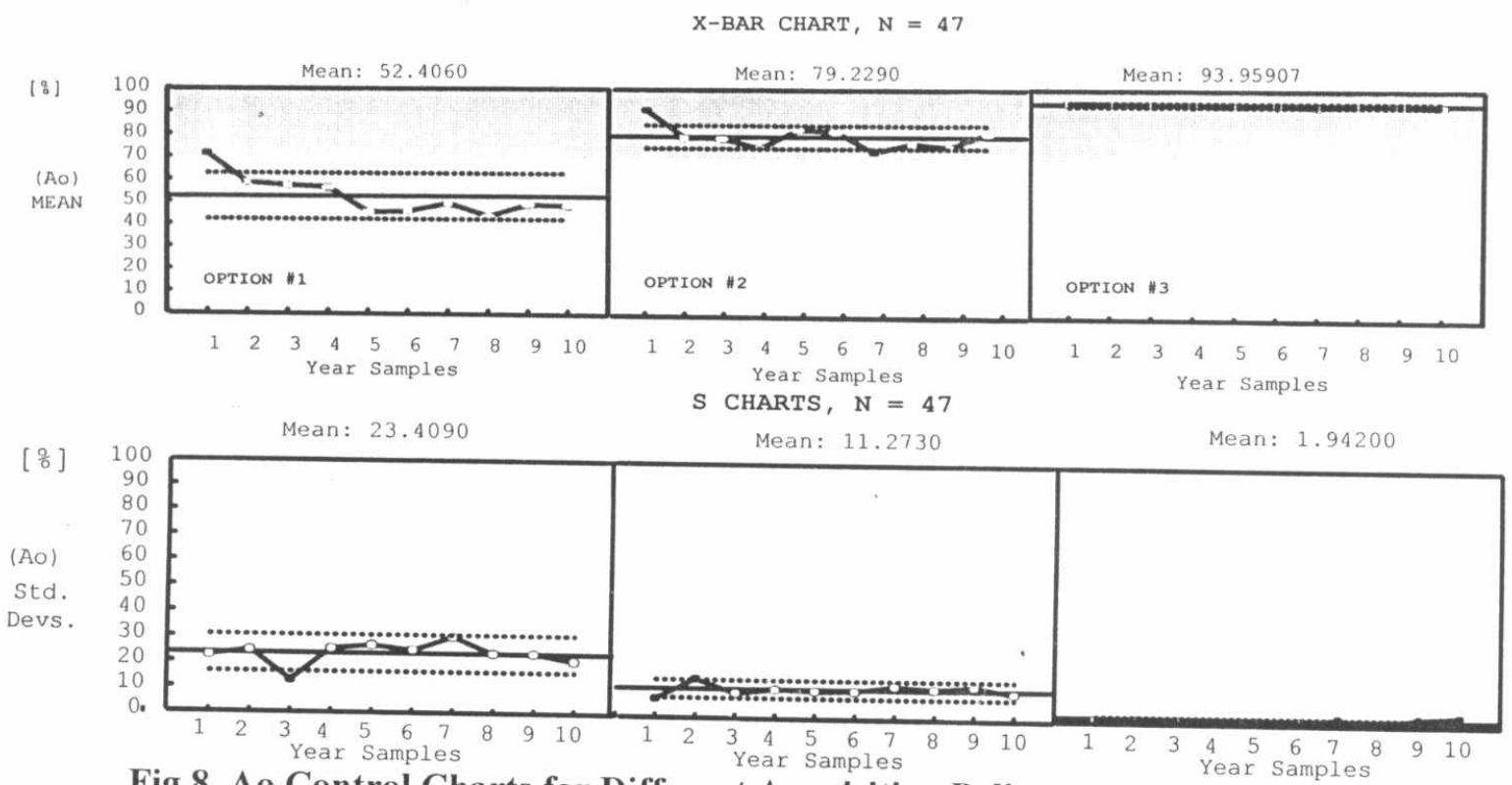

Fig.8. Ao Control Charts for Different Acquisition Polices (unstable process)

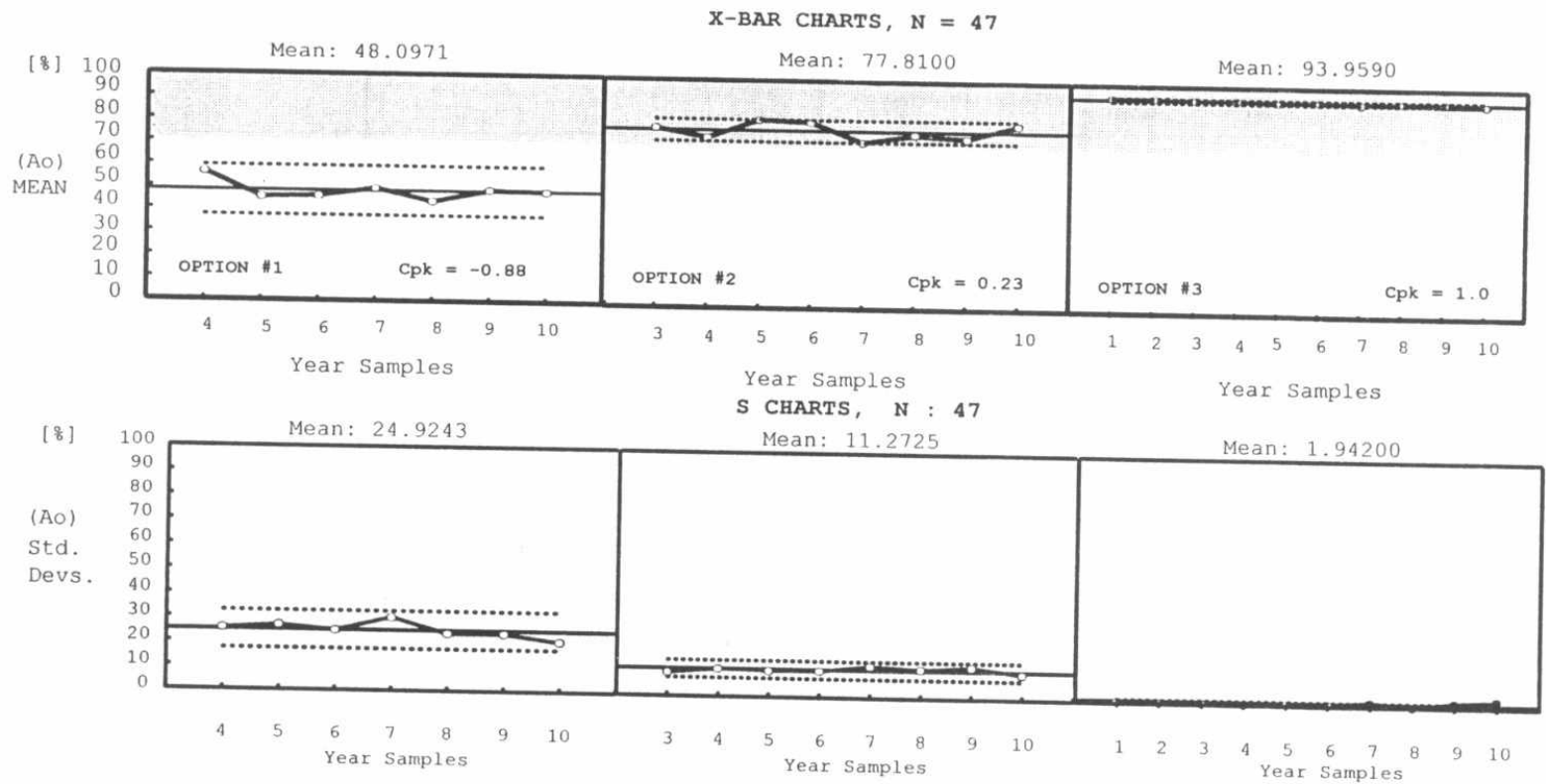

Fig.9. Ao Control Charts for Different Acquisition Polices (stable process) 
Fig.8 shows the X-BAR and $\mathrm{S}$ charts with the transient period included. In this case measurement of process capability is not possible. Fig.9 shows the X-BAR and S charts with the process stabilized and controlled by omitting the years of transient behavior. In option \# 2 , the process mean is inside the specification limits given by the aircraft user. Due to the high variability in the process output for this option, the process is incapable of providing the required availability level [Cpk $=0.23]$. In option \# 3 , the variability is reduced, mean of $A_{O}$ is increased, and the process is capable $(\mathrm{Cpk}=1)$.

Fig. 10 shows how an output distribution of $\mathrm{A}_{\mathrm{O}}$ approaches the user specification limits for the mentioned acquisition options.
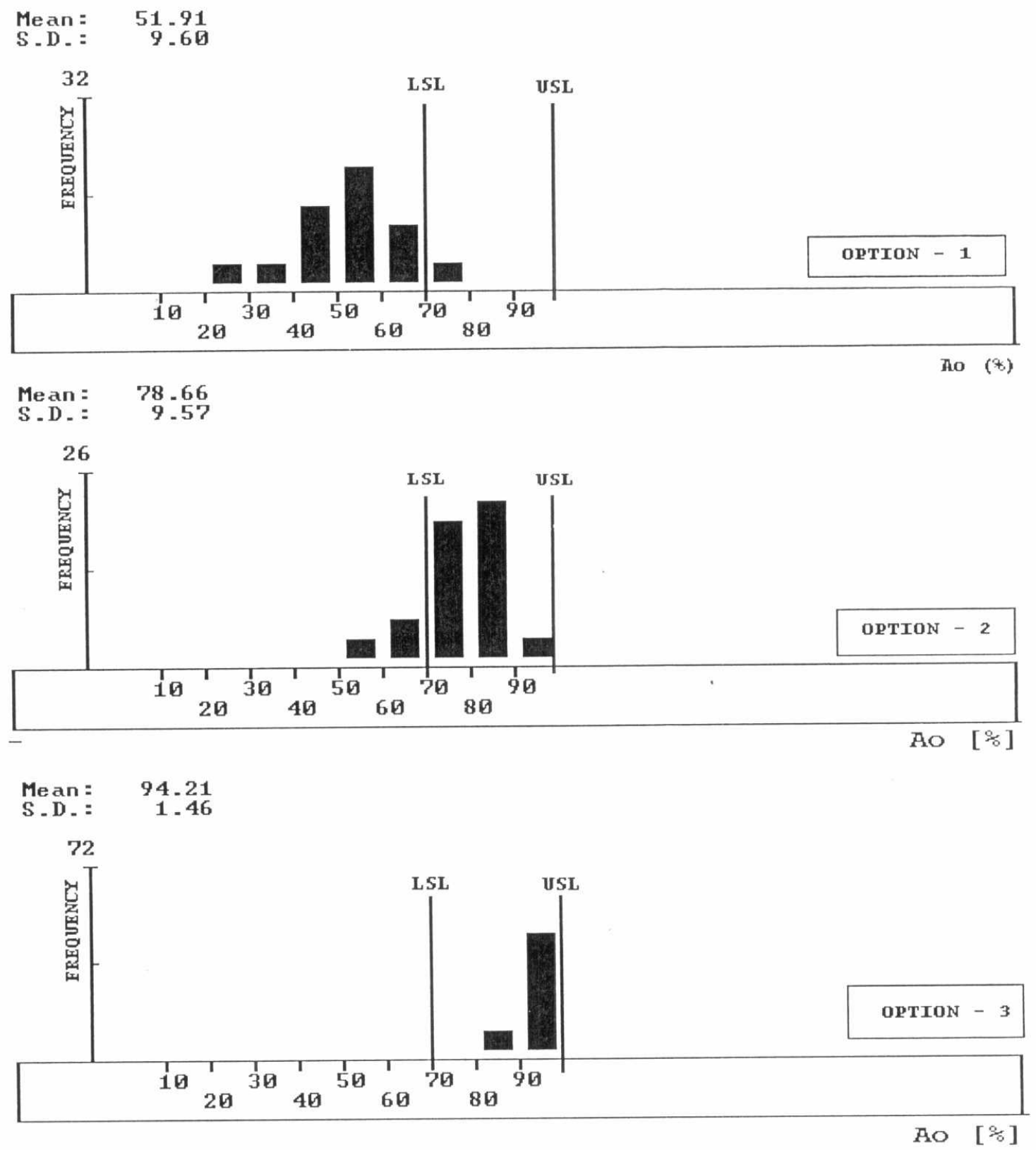

Fig.10. Ao for different acquisition options 


\section{CONCLUSION}

Working in a total quality environment, a conceptual framework and approach for developing a decision support tool during acquisition and operation of aircraft systems is proposed. In this approach, emphasis is placed on the iterative practice of continuous improvement and reduction of variation in the output of Aircraft Mission Support Process (AMSP). The concept of internal and external performance indicators is also applied. Aircraft operational availability is used as the process external performance indicator (quality characteristic). The cause and effect relationship was considered in analyzing the set of factors affecting this indicator. Using the design, support, and operational characteristics generated during the early phases of the acquisition process, it is possible through experimentation to correctly predict (AMSP) future performance. For this purpose Statistical Process Control (SPC) and process capability index (Cpk) are utilized. Application on a fleet of fighter aircraft acquisition demonstrated the power of this approach in conducting design, support, and operational tradeoffs. This is to insure that the user requirements are met and the risk of acquisition and operation is reduced.

\section{REFERENCES}

[1] Arnold G. Blair, John W. Sheppard and William R. Simpson. "A Partnership for System Support: Artificially Intelligent Maintenance Aids and CALS". Logistics Spectrum,vol.26,issue 3,summer 1992.

[2] Benjamin S. Blanchard. "Logistics In Design: Challenges for the Future". Logistics Spectrum,vol.25,issue 3,Fall 1991.

[3] Benjamin s. Blanchard. "System Engineering Management". John Wiley \& Son Inc.1991.

[4] Carl F. Asiala, Susan L. Loy, "Development of Models of Maintenance Resources Interaction, Final Report. "Mc Donnell AC, St. Louis, USA, 1979.

[5] Department of the Navy, Naval Warfare Assessment Center " Performance Indicator Measurement System " Corone, CA, USA, 1991

[6] Gan C. and Saron T. ."Structured Systems Analysis. Tools and Techniques". PrenticeHall Inc., Englewood Gliffs, 1979.

[7] Howard Gitlow, etal. "Tools and Methods for Improvement of Quality".IRWIN,1989.

[8] J. Knezevic. "Logistics Today: Mean Values, Logistics. in Future: Entire Distribution". Proceedings of the SOL, 25th Annual Symposium, 1990.

[9] Mohamed M. Elmaadawy and Atef O. Sherif "A System Study for Timing the Decision Making Process in an Air Tactical Fleet", Proceedings of First ORMA Conference, MTC, Cairo, 1984.

[10] Robert E. Stein "The Next Phase of Total Quality Management, TQM II and the focus on profitability". Marcel Dekker, Inc., New York, 1994.

[11] Stephen J. Guifoos and Lavita M. Decker. "Wartime Maintenance Impact on Aircraft Availability: Quantifying the R\&D Investment Payoff". Proceedings of the SOL,19Th. Annual Symposium,1984.

[12] Steve G. Green; Judith Laux; Robert Pizzi. "Integrated High Technology logistics with High Technology Weapon Systems". Logistics Spectrum,vol.25,issue 4, winter 1991.

[13] Timothy A. Moe. "ALE A Carrier Aircraft Availability Model". IEEE Transaction on Reliability, vol. R-25, No.4, 1976. 
[14] T.J.O Malley. "The Aircraft Availability Model: Conceptual Framework and Mathematics". Logistics Engineering Management Institute, Washington, D.C.,1983.

[15] W. Edwards Deming "Out of the Crisis", Cambridge, Mass, 1989.

\section{NOMENCLATURE}

$\mathrm{A} / \mathrm{C} \quad$ Aircraft

$\mathrm{A}_{\mathrm{O}} \quad$ Aircraft operational availability.

ABL Allocated Base Line.

AMSP Aircraft Mission Support Process.

CALS Computer-Aided Acquisition and Logistic Support.

Cpk Process Capability Index.

D Depot.

FBL Functional Base Line.

HQ Head Quarters.

HW Hardware (aircraft components).

I Intermediate.

LRU Line Replaceable Unit, i.e. aircraft component.

LSL Lower Specification Limit.

MTBD Mean Time Between Demand.

MWAIT Mission Waiting Time.

N Sample Size.

NMC Non-Mission Capable.

NRTS Not Repaired This Station Ratio.

O Organizational.

PAT Process Action Team

S Sample Standard Deviation.

SMQ Scheduled Maintenance Queue.

SPAR\$ Spare cost

SPC Statistical Process Control.

SQD Squadron.

SRU Shop Replaceable Unit, i.e. aircraft sub-component.

TQE Total Quality Environment.

TTRD Time To Repair at Depot level.

USL Upper Specification Limit.

UTR Utilization Rate.

X-BAR Sample Mean. 